\title{
Novel Redox-Responsive Amphiphilic Copolymer Micelles for Drug Delivery: Synthesis and Characterization
}

\author{
Jungeun Bae, ${ }^{1}$ Abhijeet Maurya, ${ }^{1}$ Zia Shariat-Madar, ${ }^{2}$ S. Narasimha Murthy, ${ }^{1,3}$ and Seongbong Jo ${ }^{1,4,5}$
}

Received 16 February 2015; accepted 13 June 2015; published online 27 June 2015

\begin{abstract}
A novel redox-responsive amphiphilic polymer was synthesized with bioreductive trimethyllocked quinone propionic acid for a potential triggered drug delivery application. The aim of this study was to synthesize and characterize the redox-responsive amphiphilic block copolymer micelles containing pendant bioreductive quinone propionic acid (QPA) switches. The redox-responsive hydrophobic block (polyQPA), synthesized from QPA-serinol and adipoyl chloride, was end-capped with methoxy poly(ethylene glycol) of molecular weight $750\left(\mathrm{mPEG}_{750}\right)$ to achieve a redox-responsive amphiphilic block copolymer, polyQPA-mPEG ${ }_{750}$. PolyQPA-mPEG ${ }_{750}$ was able to self-assemble as micelles to show a critical micelle concentration (CMC) of $0.039 \% \mathrm{w} / v(0.39 \mathrm{mg} / \mathrm{ml}, 0.107 \mathrm{mM})$ determined by a dye solubilization method using 1,6-diphenyl-1,3,5-hexatriene (DPH) in phosphate-buffered saline (PBS). The mean diameter of polymeric micelles was found to be $27.50 \mathrm{~nm}(\mathrm{PI}=0.064)$ by dynamic light scattering. Furthermore, redox-triggered destabilization of the polymeric micelles was confirmed by ${ }^{1} \mathrm{H}-$ NMR spectroscopy and particle size measurements in a simulated redox state. PolyQPA-mPEG ${ }_{750}$ underwent triggered reduction to shed pendant redox-responsive QPA groups and its polymeric micelles were swollen to be dissembled in the presence of a reducing agent, thereby enabling the release of loaded model drug, paclitaxel. The redox-responsive polyQPA-mPEG ${ }_{750}$ polymer micelles would be useful as a drug delivery system allowing triggered drug release in an altered redox state such as tumor microenvironments with an altered redox potential and/or redox enzyme upregulation.
\end{abstract}

KEY WORDS: amphiphilic polymer; micelle; redox-responsive polymer; targeted drug delivery; trimethyl-locked quinone propionic acid.

\section{INTRODUCTION}

Drug delivery system holds great promise as a tool to improve pharmacokinetics and therapeutic efficacy of drugs (1). In particular, anti-cancer drugs have been an active subject of targeted delivery aiming at microenvironment changes occurring at tumor sites (2). Nanotechnology is emerging as a promising tool for cancer-targeted drug delivery system because of their favorable distribution at tumor sites based on enhanced permeability and retention (3). However, important challenges associated with drug

\footnotetext{
${ }^{1}$ Department of Pharmaceutics and Drug Delivery, School of Pharmacy, The University of Mississippi, University, Mississippi 38677, USA.

${ }^{2}$ Department of BioMolecular Sciences, School of Pharmacy, The University of Mississippi, University, Mississippi 38677, USA.

${ }^{3}$ Institute for Drug Delivery and Biomedical Research (IDBR), Bangalore, India.

${ }^{4}$ Research Institute of Pharmaceutical Sciences, School of Pharmacy, The University of Mississippi, University, Mississippi 38677, USA.

${ }^{5}$ To whom correspondence should be addressed. (e-mail: seongjo@olemiss.edu)
}

delivery systems such as target tissue specificity and drug release rate at systemic sub-cellular levels to achieve maximum therapeutic efficacy but minimal toxicity often remain as obstacles to their successful translation into clinical outcomes. One approach to overcome these limitations would be designing multifunctional materials with consideration to meaningful pathophysiological changes occurring at a target site. In recent years, various drug delivery systems were explored for their properties to release encapsulated drug in a triggered manner in response to abnormal tumor microenvironments such as acidic $\mathrm{pH}$ (4), over-expressed enzymes (5), hyperthermia (6), and altered redox states (7) compared to normal tissues.

In cellular systems, redox homeostasis plays pivotal roles in the maintenance of cellular functions. Intracellular compartments maintain a certain redox gradient compared to the extracellular environment, providing an exciting target for selective intracellular chemical release. The redox gradient between intracellular and extracellular compartments in a wounded site is significantly greater than that in healthy tissues, which is modulated by intricate networks of redox signaling pathways adapting internal environment to the extracellular changes (8). Redox agents expressed during the intracellular redox-regulatory processes serve as 
indicators of the redox status. Redox-switch materials inspired by these redox agents are appealing tools to be exploited into drug delivery systems which enable to release drugs by triggering chemical/physical changes upon exposure to an altered reductive environment in cancer (9).

Various redox switches utilized to create multifunctional materials for drug delivery applications have frequently been based on diselenide and disulfide bonds (10-12). Trimethyllocked quinone propionic acid (QPA) group has also been of interest, as they can be reduced to form lactone by intramolecular cyclization of hydroquinone via the twoelectron reduction (13). The reduction of the QPA subunits associated with synthetic materials has been demonstrated by the adoption of the simulated redox states not only with chemical agents such as dithionite and borohydride, but also with reductases such as DT-diaphorase (NAD $(\mathrm{P}) \mathrm{H}$ :quinone oxidoreductase (NQO1), EC 1.6.99.2) (14,15). It is interesting to note that DT-diaphorase, a two-electron reductase, is highly expressed in several cancerous tissues $(16,17)$. Tumors such as non-small cell lung cancer and pancreatic cancers have shown to express high levels of DT-diaphorase relative to normal tissue, as much as a 20 -fold increase (18). Hence, QPA-based materials provide a wide range of redox-triggered architectures to tune the cleavage of the redox-switch for targeted drug delivery to tumors $(13,19,20)$. Volpato and coworkers prepared an aniline mustard prodrug containing QPA group to prove the prodrug activation in vitro selectively by DT-diaphorase, comparing to other reductase such as cytochrome $\mathrm{p} 450$ reductase (13). Their study has demonstrated that active aniline mustard could be released from the prodrug via DT-diaphorase-mediated bioreduction. Redoxsensitive liposomes comprising a QPA head group and dioleoyl phosphatidylethanolamine (DOPE) lipids have also been prepared by Ong et al. (21). The researchers have demonstrated that rapid lysis of the liposomes resulted in the release of incorporated calcein via liposomal structural destabilization upon reduction of QPA head group by dithionite. Recently, our group has developed redoxresponsive polymeric nanoparticles (NPs) with pendant QPA redox triggers of which aqueous solubility could be reversed upon QPA reduction. These QPA-based redoxresponsive NPs were able to release incorporated paclitaxel under a redox state simulated with dithionite. Additionally, in vitro cytotoxicity study has confirmed that these NPs could release paclitaxel in the presence of human breast tumor T47D and MDA-MD-231 cells. Although these redoxresponsive NPs offer advantages as a tumor-targeted drug delivery system, they were noticeably aggregated in aqueous environment because of hydrophobic nature of the polymer $(7,22)$. It has been found that hydrophobic polymer nanoparticles have limitations including poor stability in blood during circulation and high cytotoxicity for their potential in vivo applications (23). To overcome these limitations, we intended to obtain the polyethylene glycol (PEG)-grafted polymeric drug delivery system as the alternative approach mainly because of well-established non-fouling property of PEG that prevent the adsorption of plasma protein or the opsonization (24-26).

In this paper, we describe a novel amphiphilic block copolymer which is designed to possess QPA redox switches in the hydrophobic block while hydrophilic PEG block is expected to increase physical stability of resultant NPs. Considering the capability of QPA reduction in the presence of meaningful tumor-associated redox changes, we anticipate that polymer micelles consisting of QPA redox switches can be destabilized by a solubility reversal occurring in the hydrophobic polymer block of the copolymer due to the release of pendant QPA groups. To our knowledge, this is the first study reporting the incorporation of QPA redox switches in the polymeric micellar system for a drug delivery application.

\section{EXPERIMENTAL}

\section{Materials}

Methanesulfonic acid; 2,3,5-trimethyl hydroquinone; methyl $\beta, \beta$-dimethylacrylate; 2-amino-1,3-propanediol; and adipoyl chloride were obtained from Alfa Aesar (Ward Hill, MA). Adipoyl chloride was distilled under reduced pressure before the reaction. Paclitaxel (PTX) was purchased from LC Laboratories ${ }^{\circledR}$ (Woburn, MA). Methoxy poly(ethylene gly$\mathrm{col})$ of molecular weight $750\left(\mathrm{mPEG}_{750}\right)$ from Sigma-Aldrich (St. Louis, MO) was used after distillation. Acetone- $d_{6}$ (99.9\%, Cambridge Isotope Laboratories, Inc., Andover, MA) and deuterium oxide (99.8\%, Acros) were used for NMR measurements as received. Human DT-diaphorase and reduced dipotassium salt $\beta$-nicotinamide adenine dinucleotide $(\beta-\mathrm{NADH})$ were purchased from Sigma-Aldrich (St. Louis, MO). All other chemicals purchased from Fisher Scientific (Pittsburg, PA) were used as received.

\section{Synthesis of Amphiphilic Redox-Sensitive Polymer (polyQPA-mPEG ${ }_{750}$ )}

PolyQPA-mPEG 750 was synthesized in a two-step reaction shown in Scheme 1. First, redox-responsive hydrophobic block, polyQPA, was synthesized as reported previously $(7,22)$. Briefly, fresh distilled adipoyl chloride diluted in anhydrous tetrahydrofuran (THF) was slowly added into a solution of the monomer, QPA-serinol, at a molar ratio of 1:1 in pyridine (10 times molar amount of adipoyl chloride) at room temperature and stirred for $30 \mathrm{~min}$. After further polymerization under dry nitrogen at room temperature overnight, an additional amount of adipoyl chloride (another $10 \%$ of initial molar amount) in THF was charged to the reaction mixture and stirred for another $6 \mathrm{~h}$. Next, $\mathrm{mPEG}_{750}$ was dried by azeotropic distillation using toluene to end-cap polyQPA. Dried $\mathrm{mPEG}_{750}$ in THF was added to polyQPA at a molar ratio of 10:1 and the end-capping reaction was proceeded for another $16 \mathrm{~h}$. Resultant polyQPA-mPEG 750 was precipitated in an excess amount of ether and the crude polymer was purified further by rinsing three times with methanol to remove unreacted $\mathrm{mPEG}$. The final product polyQPA$\mathrm{mPEG}_{750}$ was yielded as yellow solid $(62.1 \%)$.

${ }^{1} \mathrm{H}-\mathrm{NMR}\left(\mathrm{CDCl}_{3}\right)$ : $\delta$ ppm: $4.37(14 \mathrm{H}, \mathrm{s}), 4.12(28 \mathrm{H}, \mathrm{s})$, $4.06(28 \mathrm{H}, \mathrm{s}), 3.64(90 \mathrm{H}, \mathrm{s}), 3.30(6 \mathrm{H}, \mathrm{s}), 2.83(28 \mathrm{H}, \mathrm{s}), 2.36$ $(56 \mathrm{H}, \mathrm{t}), 2.12(42 \mathrm{H}, \mathrm{s}), 1.95(56 \mathrm{H}, \mathrm{m}), 1.39(14 \mathrm{H}, \mathrm{s})$. 

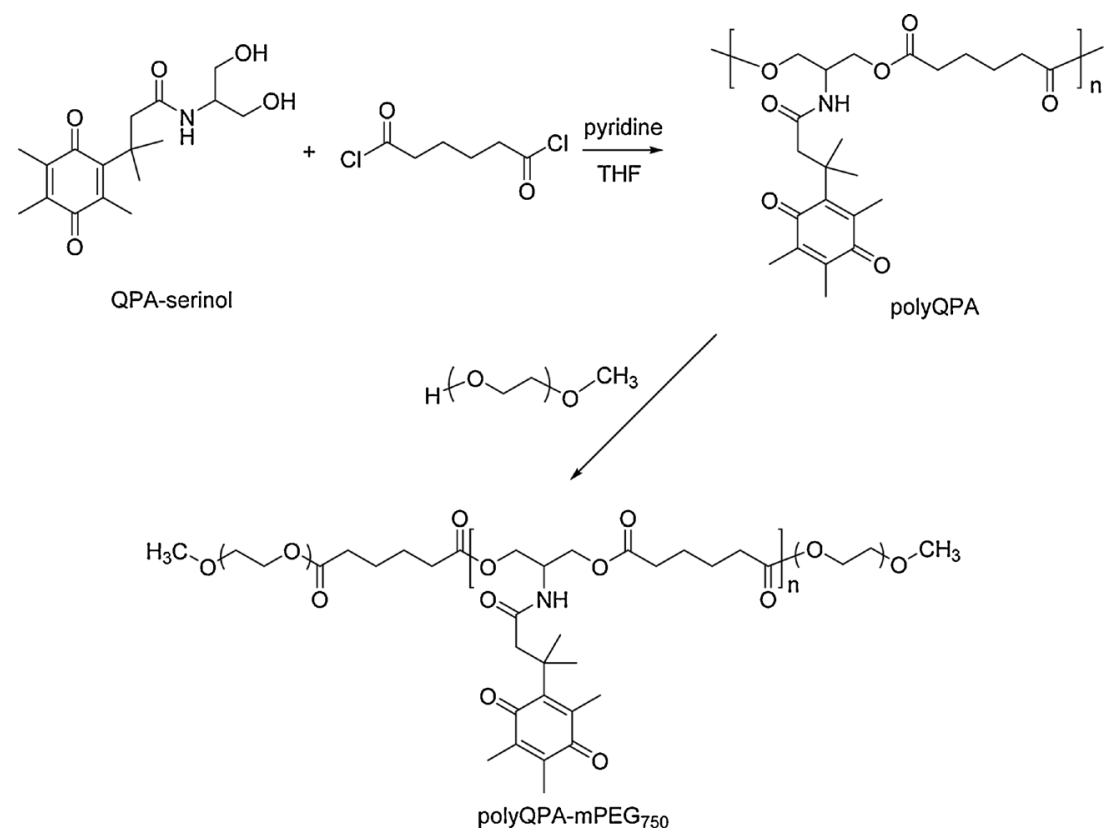

Scheme 1. Reaction scheme for the synthesis of redox-responsive amphiphilic block copolymer, polyQPA-mPEG $\mathrm{P}_{750}$, with QPA redox switches

\section{Characterization of polyQPA-mPEG 750}

The chemical structures of the polyQPA-mPEG ${ }_{750}$ were identified with $\mathrm{H}^{1}$-NMR spectrum using a Bruker Avance $400 \mathrm{MHz}$ spectrometer. The NMR spectra were measured in $\mathrm{CDCl}_{3}$. The molecular weight and polydispersity index (PI) of the synthesized copolymer were determined with a Waters gel permeation chromatography (GPC) system (Waters, Milford, MA). The GPC instrument is equipped with a binary pump (Waters 1525), refractive index detector (waters 2414), and a Styragel HR4E column $(300 \times 7.8 \mathrm{~mm}$ ID, $5-\mu \mathrm{m}$ particle size $)$. HPLC grade tetrahydrofuran (THF) was run as a mobile

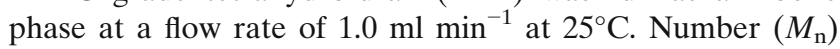
and weight average $\left(M_{\mathrm{w}}\right)$ molar masses were determined using Breeze software. The molecular weight of the copolymer was calculated using a calibration curve obtained from polystyrene standards (Polysciences, Inc., Warrington, $\mathrm{PA}$ ) of molecular weights ranging from 600 to $50,000 \mathrm{~g} \mathrm{~mol}^{-1}$ in THF.

\section{Preparation of Polymeric Micelles}

Drug-free and PTX-loaded polymeric micelles were prepared by a method of a solid dispersion technique with a minor modification (27). Briefly, PTX (32.2 mg) and polyQPA-mPEG $750(150 \mathrm{mg})$ were completely dissolved in $2 \mathrm{ml}$ of acetonitrile. After evaporation of the organic solvent using a rotary evaporator, remaining organic solvent was further removed by a vacuum pump overnight to obtain the molecularly dispersed PTX in polymer matrix. Three milliliters of phosphate-buffered saline (PBS, pH 7.4) were added to the mixture to obtain micellar solution by hydration. After being stirred overnight in the dark at room temperature, the solution was filtered through a $0.2-\mu \mathrm{m}$ filter to remove the unincorporated drug aggregates, followed by lyophilization.
The blank micelles were prepared by the same procedure without PTX.

The loading efficiency of PTX in the micelles was determined by the HPLC method previously reported to analyze the amount of PTX in QPA polymer NPs (22). The drug loading efficiency (\%) was calculated according to the following formula.

PTXloading $(\%)=($ amount of loaded PTX/amount of initially added PTX $) \times 100$

\section{CMC Measurement}

The critical micelle concentration (CMC) of the polymer was determined by a dye solubilization method using 1,6diphenyl-1,3,5-hexatriene (DPH) (28,29). Briefly, serially diluted polymer solutions in a concentration range of $1.0 \times 10^{-4}$ to $1.0 \mathrm{wt} \%$ were prepared with PBS. Next, $25 \mu \mathrm{l}$ of $0.4 \mathrm{mM}$ DPH solution in methanol was added into $2.5 \mathrm{ml}$ of each polymer solution. The mixture was sonicated for $1 \mathrm{~min}$ and equilibrated for $24 \mathrm{~h}$ in a dark place. Measurements of UV absorption for each solution were taken on a Genesys 6 UV-Visible scanning spectrophotometer (Thermo Scientific, Massachusetts) at wavelengths of 377 and $391 \mathrm{~nm}$. The absorbance difference at 377 and $391 \mathrm{~nm}$ was plotted against polymer concentration. The CMC of polyQPA-mPEG 750 was determined by reading the polymer concentration at which the extrapolated two lines cross over.

\section{Particle Size Measurements and Redox-Responsive Polymer Degradation}

The Z-average diameter and polydispersity index (PI) of polyQPA-mPEG ${ }_{750}$ micelles were determined by dynamic 
light scattering using a Zetasizer Nano ZS (Malvern Instruments, Worcestershire, UK). A polyQPA-mPEG ${ }_{750}$ solution at a concentration above its $\mathrm{CMC}$ was prepared to allow selfassembling into micelles in PBS.

The effect of QPA reduction on the micellar structure was tested with a chemical reducing agent, sodium dithionite $\left(\mathrm{Na}_{2} \mathrm{~S}_{2} \mathrm{O}_{4}\right)$. QPA lactone release was identified by ${ }^{1} \mathrm{H}-\mathrm{NMR}$ spectrum. A polyQPA-mPEG ${ }_{750}$ solution at a concentration of $1.5 \%(w / v)$ was prepared for the NMR measurement using a co-solvent of acetone- $d_{6}$ and deuterium oxide at a volume ratio of 1:2. The NMR spectrum of release QPA lactone was measured on the NMR spectrophotometer and compared with that of QPA lactone control synthesized during polymer synthesis (13). The NMR spectra were periodically taken up to $3 \mathrm{~h}$ after the addition of sodium dithionite.

\section{Redox-Triggered QPA Lactone Release from polyQPA-mPEG ${ }_{750}$ Micelles}

QPA lactone release from the micelles was examined by challenging polyQPA-mPEG ${ }_{750}$ micelles with two different redox triggers, sodium dithionite and DT-diaphorase. A polyQPA-mPEG ${ }_{750}$ stock solution at a concentration of $10 \mathrm{mg} \mathrm{ml}^{-1}(1 \%)$ in PBS was prepared and diluted to obtain polymer solutions at concentrations of $0.01 \%$ and $0.5 \%$. Fifteen milligrams of sodium dithionite resulting in a final concentration of $29 \mathrm{mM}$ was added to $3 \mathrm{ml}$ of each polyQPA$\mathrm{mPEG}_{750}$ solution. In the case of enzymatic reduction of QPA, five units of DT-diaphorase and bovine serum albumin $(0.007 \%)$ were added to each PolyQPA-mPEG ${ }_{750}$ solution. After the addition of an amount of $\beta-\mathrm{NADH}$ to achieve a final concentration of $2 \mathrm{mM}, 150 \mu \mathrm{l}$ of the medium was collected and mixed into $150 \mu \mathrm{l}$ of acetonitrile at predetermined time points. All samples were tested in triplicate and the study was carried out in a water bath equilibrated at $37^{\circ} \mathrm{C}$. Amounts of QPA lactone released upon reduction were analyzed using the HPLC method previously reported. A HPLC system equipped with a Luna C18(2) HPLC column (Phenomenex, $150 \times 4.6 \mathrm{~mm}, 5 \mu \mathrm{m}$ ), a binary pump (Waters 1525 ), and an auto-sampler (Water 717) was used to run a mixture of acetonitrile and water at $55: 45 \% \mathrm{v} / \mathrm{v}$ as a mobile phase at a flow rate of $1 \mathrm{ml} \mathrm{min}^{-1}$ after injecting a $20-\mu l$ sample (30). Released QPA lactone was detected at a wavelength of $227 \mathrm{~nm}$ on a UV detector (Water 2487). The amount of released lactone was calculated using a calibration curve obtained from known concentrations of QPA lactone solutions in acetonitrile.

\section{In Vitro Drug Release Study}

In vitro drug release from polyQPA-mPEG ${ }_{750}$ micelles was examined by challenging the micellar solution with sodium dithionite to reduce QPA groups after loading PTX in micelles as a model drug. Based on a HPLC measurement performed prior to drug release study, it was shown that $1 \mathrm{mg}$ of polyQPA-mPEG ${ }_{750}$ micelle contained $177.4 \mu \mathrm{g}$ of PTX. One hundred microliters of $0.5 \%$ of PTX loaded polymer micelles containing $88.7 \mu \mathrm{g}$ of PTX was used for the study. Forty milliliters of PBS including sodium salicylate at a concentration of $0.8 \mathrm{M}$ were used for redox-triggered drug release. After placing polyQPA-mPEG ${ }_{750}$ micelle in a dialysis membrane of MWCO 1000 Da (Spectrum Laboratories), the dialysis membrane was immersed in drug release media equilibrated at $37^{\circ} \mathrm{C}$ and the release media were continuously agitated by magnetic stirring. For redox-triggered PTX release from polyQPA-mPEG ${ }_{750}$ micelles, an amount of sodium dithionite to achieve a final concentration of $29 \mathrm{mM}$ was added in the medium. In addition, the solution consisting of PTX $(88.7 \mu \mathrm{g})$ was utilized as a control. Samples were withdrawn from the release medium at predetermined time points and were analyzed by HPLC.

\section{Cell Culture}

Human breast tumor T47D and MDA-MB-231 cells lines were purchased from ATCC, Manassas, VA, and used in this work. These cell lines were cultured in DMEM/F12 medium containing $2.5 \mathrm{mM}$ l-glutamine (Mediatech), supplemented with fetal bovine serum (FBS, $10 \% v / v$ final concentration, Hyclone), penicillin $G$ (sodium salt, 50 units $\mathrm{ml}^{-1}$ ) and streptomycin sulfate $\left(50 \mu \mathrm{g} \mathrm{ml}^{-1}\right)$ (BioWhittaker). Exponentially grown cells were plated at the density of 30,000 cells per well into 96-well plates in a volume of 100 $\mu \mathrm{L}$ culture media and incubated at $37^{\circ} \mathrm{C}$ in a humidified environment (95\% air, $\left.5 \% \mathrm{CO}_{2}\right)$ as previously reported (31).

\section{In Vitro Antitumor Activity of polyQPA-mPEG ${ }_{750}$ Micelles}

The cytotoxicity of PTX formulated in polyQPA$\mathrm{mPEG}_{750}$ was evaluated in human breast tumor T47D and MDA-MB-231 cells lines, in comparison to free PTX. Briefly, after seeing in 96-well plates followed by overnight attachment, the cells were treated by PTX-loaded micelles with varied concentrations. Free PTX, at concentrations equivalent to the PTX incorporated in micelles, was also added into cells. After treatment for $24 \mathrm{~h}$, the cells were further incubated and cell viability was determined by a sulforhodamine B (SRB) method (32). Optical density (OD) was measured at $490 \mathrm{~nm}$ with background absorption at $630 \mathrm{~nm}$. Data were normalized to the untreated control and presented as "\% of control," using the formula.

Cell viability $(\%$ of control $)=\left(\mathrm{OD}_{\text {treated }} / \mathrm{OD}_{\text {control }}\right) \times 100$

\section{Statistical Analysis}

Experimental measurements were triplicated for each sample. The results are presented as mean \pm standard deviation. The statistical analysis of experimental data utilized the student's $t$ test and statistical significance was considered for $p$ values $<0.05$.

\section{RESULTS}

\section{Synthesis and Characterization of polyQPA-mPEG ${ }_{750}$}

PolyQPA-mPEG ${ }_{750}$, designed for redox-responsive polymer micelles, were synthesized as illustrated. After synthesis of hydrophobic block, polyQPA, as presented in Scheme 1, the following reaction with an additional amount of adipoyl 
chloride provided reactive end groups in polyQPA. The reactive polyQPA underwent end-capping with $\mathrm{mPEG}$ of molecular weights 750 to achieve redox-sensitive block copolymers. The ${ }^{1} \mathrm{H}-\mathrm{NMR}$ spectrum of polyQPA-mPEG ${ }_{750}$ in Fig. 1 showed the peaks of $\mathrm{mPEG}$ at $\delta=3.64 \mathrm{ppm}$ ($\left.\mathrm{CH}_{2} \mathrm{CH}_{2} \mathrm{O}_{-}\right)$and 3.37 ppm $\left(\mathrm{CH}_{3} \mathrm{O}_{-}\right)$in $\mathrm{CDCl}_{3}$. Moreover, three methyl $\left(\mathrm{CH}_{3}-\right)$ protons of quinone was presented at 1.95-1.96 and $2.12 \mathrm{ppm}$. Resultant polyQPA-mPEG 750 was obtained as a yellow solid exhibited good water solubility.

Number average molecular weight $\left(M_{n}\right)$ and polydispersity (PI) of the redox-sensitive block copolymer were determined to be 3640 and 1.65, respectively, by GPC. Clear shift in the molar mass distribution to shorter retention times was observed. Before the end-capping of the PEG at the end of the hydrophobic group, the molecular weight of hydrophobic polymer was calculated as 2482 with PI of 1.37 by GPC measurements.

\section{Micelle Formulation}

The ability of polyQPA-mPEG $\mathrm{F}_{750}$ to self-assemble into micelles was examined by a CMC measurement. The CMC of polyQPA-mPEG $\mathrm{m}_{750}$ was determined by a method based on hydrophobic dye solubilization as shown in Fig. 2. At a concentration below $\mathrm{CMC}$, amphiphilic polyQPA-mPEG 750 was not able to increase DPH solubility, resulting in inadequate UV absorbance. A dramatic increase in UV absorbance was observed at a polymer concentration greater than CMC. The CMC was determined by a graphical extrapolation of two phases of UV absorbance changes and reading out the polymer concentration at which they crossed over. The CMC of polyQPA-mPEG $\mathrm{C}_{750}$ in PBS was found to be $0.039 \% \mathrm{w} / v(0.39 \mathrm{mg} / \mathrm{ml}, 0.107 \mathrm{mM})$ at $25^{\circ} \mathrm{C}$.
Both PTX-free and PTX-loaded polymeric micelles were prepared by a solid dispersion technique which was also applied to prepare for PTX-loaded polymer micelles from monomethoxy poly(ethylene glycol)-block-poly(D,L-lactide) (mPEG-PDLLA) (27). During the process of micelle preparation, the amount of residual acetonitrile, the solvent to dissolve polyQPA-mPEG 750 and PTX, was under the detection limit by ${ }^{1} \mathrm{H}$ NMR spectroscopy measurements after vacuum drying. A simple hydration of the mixture of polyQPA-mPEG ${ }_{750}$ and PTX with PBS enabled to produce micelle formulations.

The mean diameter of resultant PTX-free micelles was determined to be $27.50 \mathrm{~nm}$ with a PI of 0.064 at $25 \pm 1^{\circ} \mathrm{C}$ by dynamic light scattering (DLS) as presented in Fig. 2. However, the average size of PTX-loaded micelles was $79.92 \mathrm{~nm}$, which was noticeably larger than that of PTX-free micelles. The amount of PTX loaded in $1 \mathrm{mg}$ of polyQPA$\mathrm{mPEG}_{750}$ micelles was found to be $177.4 \mu \mathrm{g}$ indicating a loading content of $17.74 \%$ while drug loading efficiency was found to be $82.5 \%$.

\section{Redox-Responsive Polymer Degradation}

PolyQPA-mPEG ${ }_{750}$ was examined for its reduction in the presence of a redox chemical. Since we are interested in redox-triggered drug release from polyQPA-mPEG $\mathrm{m}_{750} \mathrm{mi}$ celles, we primarily focused on the characterization of dimensional changes occurring to the micelles in the presence of a redox chemical. This would be eventually translated into drug release. As shown in Fig. 3, the micellar size based on averaged volume has significantly changed upon the addition of a redox chemical, sodium dithionite. The size of polyQPA$\mathrm{mPEG}_{750}$ micelles rapidly increased from 28 to $64 \mathrm{~nm}$ within

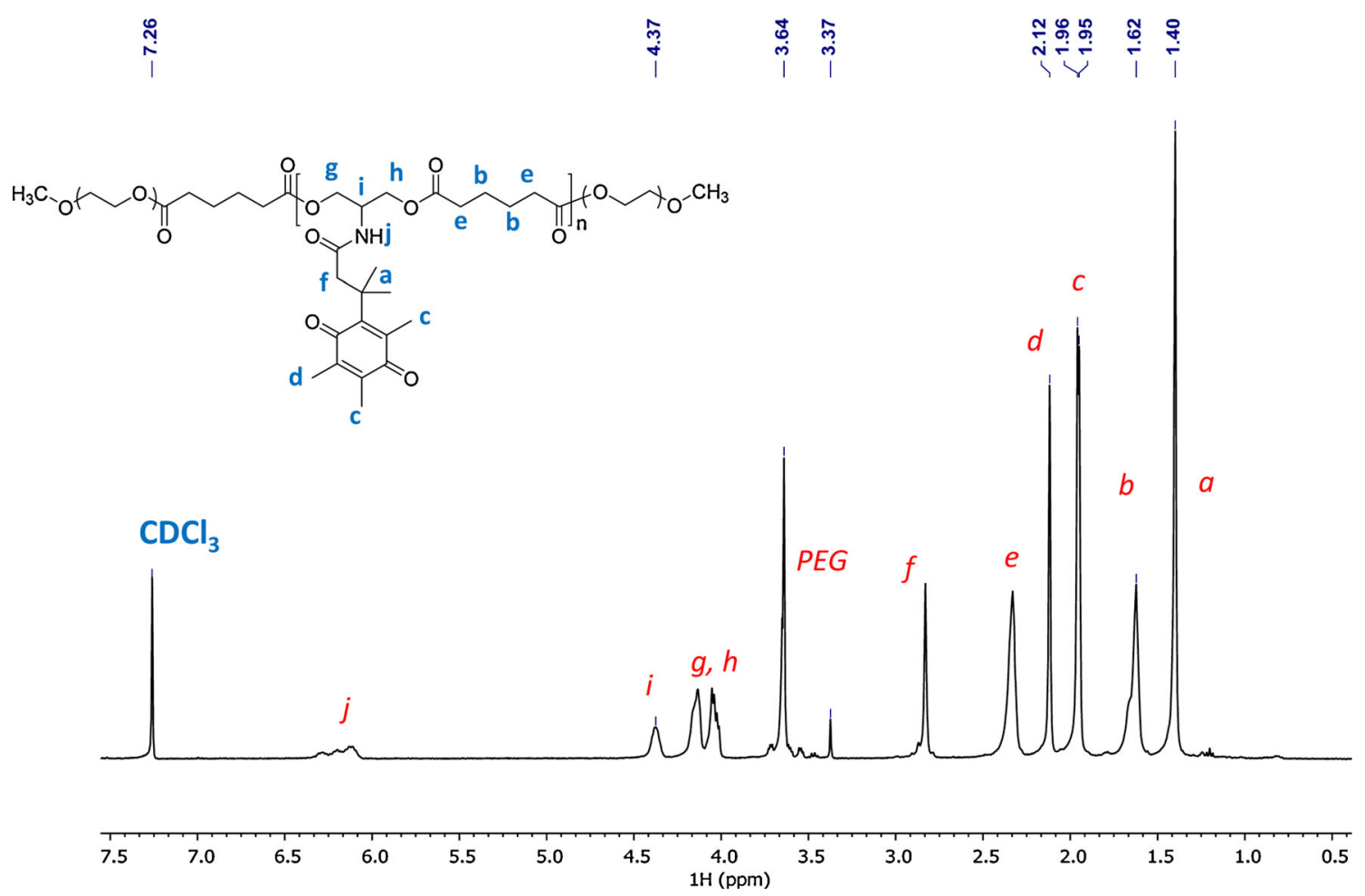

Fig. 1. ${ }^{1} \mathrm{H}-\mathrm{NMR}$ spectrum of polyQPA-mPEG 750 in $\mathrm{CDCl}_{3}$. The letters denote peak assignments in ${ }^{1} \mathrm{H}-\mathrm{NMR}$ spectra 

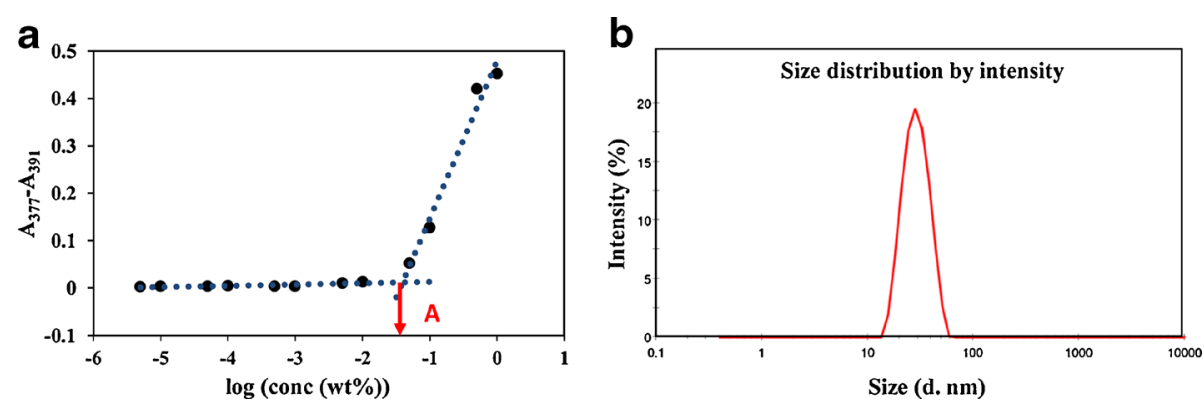

Fig. 2. a Determination of the critical micelle concentration of polyQPA-mPEG ${ }_{750}$ using DPH. The difference in the absorbance intensities of DPH at wavelengths of 377 and $391 \mathrm{~nm}$ was plotted as a function of polyQPA-mPEG ${ }_{750}$ concentration. $\mathrm{CMC}$ was determined by reading out the point, $A$, at which two extrapolated lines were crossed. b A representative particle size distribution of drug-free micelles was obtained by DLS measurement at $25 \pm 1^{\circ} \mathrm{C}$. Determined average particles size was $27.50 \mathrm{~nm}$ with a PI of 0.064

5 min after the addition of sodium dithionite while no noticeable change in micellar size was observed from the control without sodium dithionite. The average size of micelles further increased to reach $3338 \mathrm{~nm}$ at a time point of $30 \mathrm{~min}$. The increase in polyQPA-mPEG $\mathrm{m}_{750}$ micelle size in the presence of sodium dithionite is attributed to the solubility reversal occurred to the hydrophobic polyQPA core which would become hydrophilic after the removal of hydrophobic pendant QPA groups via intramolecular cyclization. In addition, PI of the NPs increased over $3 \mathrm{~h}$ indicating more heterogeneous particle population.

The effect of sodium dithionite on polyQPA-mPEG $\mathrm{F}_{750}$ was directly examined by NMR measurement. Figure 4a has shown reduction mechanism of QPA switches in polyQPA$\mathrm{mPEG}_{750}$ copolymer with sodium dithionite and the letters in Fig. 4a indicate peak assignments in ${ }^{1} \mathrm{H}-\mathrm{NMR}$ spectra. After dissolving polyQPA-mPEG 750 in a co-solvent of acetone- $d_{6}$ : $\mathrm{D}_{2} \mathrm{O}(2: 1, v / v)$ to warrant the solubility of both lactone and copolymer, NMR spectra were periodically recorded with or without sodium dithionite shown in Fig. 4b (1-3). Figure 4b also includes the NMR spectrum of QPA lactone as control to compare with (Fig. 4B-4). When sodium dithionite was added into micelle solution, all proton peaks in NMR spectra (Fig. 4b) were slightly shifted $(<0.25 \mathrm{ppm})$ compared to the one recorded before adding sodium dithionite. This result is because of ionic strength changes in the NMR sample

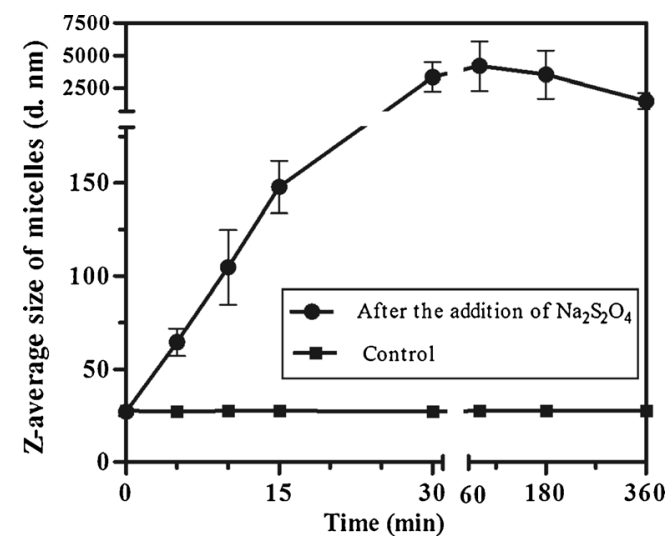

Fig. 3. Redox-triggered particle size change in polyQPA-mPEG ${ }_{750}$ micelles was monitored by dynamic light scattering measurements in the presence or absence of sodium dithionite solution and the similar result were presented in the reported publication $(33,34)$. The addition of sodium dithionite also resulted in the appearance of proton peaks attributed to six protons of methyl groups in QPA lactone at $\delta=$ $1.33 \mathrm{ppm}$. In addition, $30 \mathrm{~min}$ after the initiation of reduction, the proton peak from QPA pendant groups in polyQPA-mPEG ${ }_{750}\left(-\mathrm{COCH}_{2} \mathrm{C}-\right)$ has shifted from $\delta=2.75$ to $2.51 \mathrm{ppm}$, indicating the QPA lactone formation by intramolecular cyclization.

\section{Redox-Triggered QPA Lactone Release from polyQPA-mPEG ${ }_{750}$ Micelles}

In order to quantitatively analyze QPA reduction in polyQPA-mPEG ${ }_{750}$ micelles, the amount of QPA lactone released from polyQPA-mPEG ${ }_{750}$ was measured as a function of time in the presence and absence of the redox agent. As shown in Fig. 5, there was no noticeable QPA lactone release from the control which did not contain the redox agent. QPA reduction in polyQPA-mPEG $\mathrm{m}_{750}$ micelles was rapid enough to release $60.04 \%$ and $67.04 \%$ of QPA groups at polymer concentrations of $0.01 \%$ and $0.50 \%$, respectively, in $30 \mathrm{~min}$ after the initiation of the reduction. Cumulative QPA lactone release reached to $85.30 \%$ and $72.62 \%$ within $24 \mathrm{~h}$ at polymer concentrations of $0.01 \%$ and $0.50 \%$, respectively. At $48 \mathrm{~h}$ after the addition of sodium dithionite, QPA lactone generated from $0.01 \%$ of polyQPA-mPEG was $88.09 \%$ which reveals no statistically significant differences (two-tailed $t$ test, $p>0.05$ ) even after $48 \mathrm{~h}$ of incubation.

In addition, polyQPA-mPEG ${ }_{750}$ micelles were also able to release QPA lactone via redox enzyme-mediated bioreduction. Indeed, DT-diaphorase could trigger QPA reduction to result in spontaneous QPA lactone release from hydrophobic cores of polyQPA-mPEG 750 micelles. DTdiaphorase-mediated QPA reduction, however, was dependent on polymer concentration. Cumulative amounts of QPA lactone released by five units of DT-diaphorase in the presence of $2 \mathrm{mM}$ of a cofactor $\beta-\mathrm{NADH}$ at $37^{\circ} \mathrm{C}$ reached to $61.84 \%$ and $20.87 \%$ at polymer concentrations of $0.01 \%$ (Fig. 5b), a concentration below CMC, and $0.50 \%$ (Fig. 5a), a concentration above CMC, respectively. This result indicated that the supramolecular structure of polyQPA-mPEG ${ }_{750}$ assembly could affect the efficiency of DT-diaphorasemediated QPA reduction. 


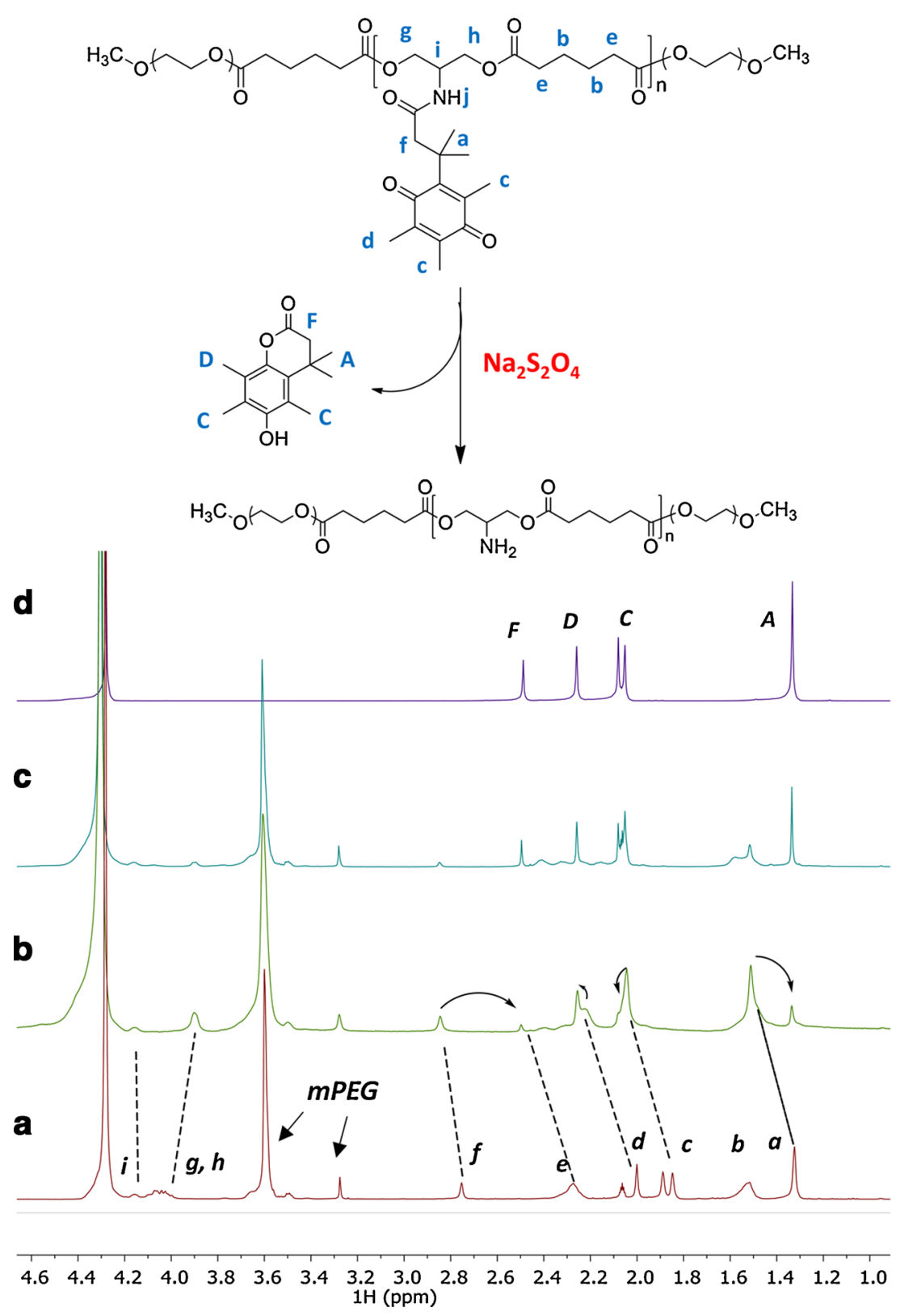

Fig. 4. a Reduction mechanism of redox switches in polyQPA-mPEG $\mathrm{F}_{750}$ copolymer using sodium dithionite and release of QPA lactone. The letters denote peak assignments in ${ }^{1} \mathrm{H}$ NMR spectra. b ${ }^{1} \mathrm{H}-\mathrm{NMR}$ spectra $(400 \mathrm{MHz})$ of polyQPA-mPEG 750 were recorded in acetone- $d_{6}$ and deuterium oxide $(1.5 \%, 1: 2, w / v)$ before (B-1) and after (B-2, $30 \mathrm{~min}$, and $\mathrm{B}-3,3 \mathrm{~h}$ ) an addition of sodium dithionite at a concentration of $29 \mathrm{mM}$. The NMR spectrum of lactone (B-4) is also measured for comparison

\section{In Vitro PTX Release from polyQPA-mPEG 750 Micelles}

In vitro PTX release from polyQPA-mPEG 750 micelles, examined by a dialysis method in the presence of sodium dithionite, demonstrated that QPA reduction in polyQPA$\mathrm{mPEG}_{750}$ micelles could trigger the release of incorporated PTX. As seen in Fig. 6, polyQPA-mPEG ${ }_{750}$ micelles have released only $17.08 \%$ of loaded PTX over a period of $36 \mathrm{~h}$ in the absence of sodium dithionite. An addition of the redox agent into the polyQPA-mPEG F50 $_{75}$ micellar solution has dramatically increased the release of PTX resulting in a significant increase in cumulative release of PTX from
$18.20 \%$ to $52.53 \%$ between time points of 3 and $12 \mathrm{~h}$, respectively $(p<0.05)$. The cumulative PTX release has further increased to $65.73 \%$ at $36 \mathrm{~h}$ after triggering QPA reduction. Triggered PTX release from polyQPA-mPEG ${ }_{750}$ micelles was comparable to the PTX release profile from pure PTX solution.

\section{In Vitro Antitumor Activity of polyQPA-mPEG ${ }_{750}$ Micelles}

Concentration-dependent cell cytotoxicity studies were performed to determine the effects of PTX-loaded polyQPAmPEG micelles on the proliferation/viability of human breast 

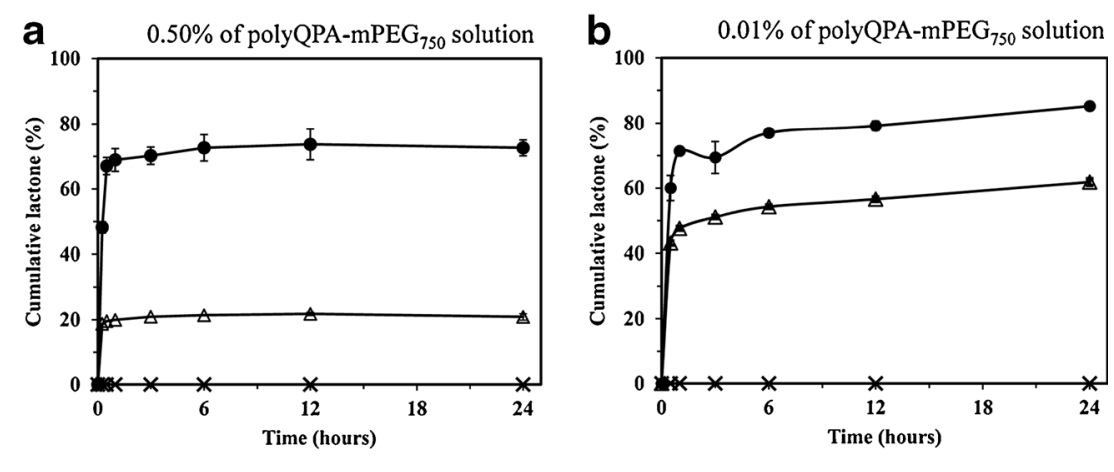

- - Sodium dithionite

$\Delta$ - DT-diaphorae/ $/ \mathrm{NADH}$

$x$ - Control

Fig. 5. Redox-triggered QPA lactone release from polyQPA-mPEG ${ }_{750}$ solution in PBS buffer $\left(\mathrm{pH} \mathrm{7.4)}\right.$ at $37^{\circ} \mathrm{C}$. Cumulative QPA lactone release from polyQPA-mPEG $\mathrm{F}_{750}$ at concentrations of $0.50 \%$ (a) and $0.01 \%$ (b) was plotted as a function of time after an addition of each reducing agent, sodium dithionite (circles) or DT-diaphorae/ $\beta-\mathrm{NADH}$ (triangles). The control (crosses) were copolymers without those reducing agents

tumor cells. As shown in Fig. 7a, at a drug dose of $0.1 \mu \mathrm{M}$, cell viabilities of $20 \%$ and $24 \%$ were observed for MDA-MB-231 cell line following $24 \mathrm{~h}$ of incubation with free PTX and PTXloaded micelles, respectively. The cell experiment for T47D cell line in Fig. $7 \mathrm{~b}$ also showed similar cell viability, in which $22 \%$ and $26 \%$ of cell viability were observed for plain drug, PTX loaded micelles, respectively. The $\mathrm{IC}_{50}$ (i.e., inhibitory concentration to produce $50 \%$ cell death) of PTX-loaded micelles, were 217.6 and 277.0 $\mu \mathrm{M}$ for MDA-MB-231 and T47D cell lines, respectively, while those of free PTX were 323.3 and $296.1 \mu \mathrm{M}$.

\section{DISCUSSION}

We have previously reported QPA-based redox-responsive polymeric NPs enabling drug release under a simulated redox state. In this study, we developed a redox-responsive amphiphilic block copolymer containing QPA triggers, polyQPA-mPEG ${ }_{750}$, which is able to self-assemble into micelles, load a hydrophobic drug, and release the drug in response to a redox change. Redox-responsive copolymers were synthesized in a two-step reaction. In the first step in

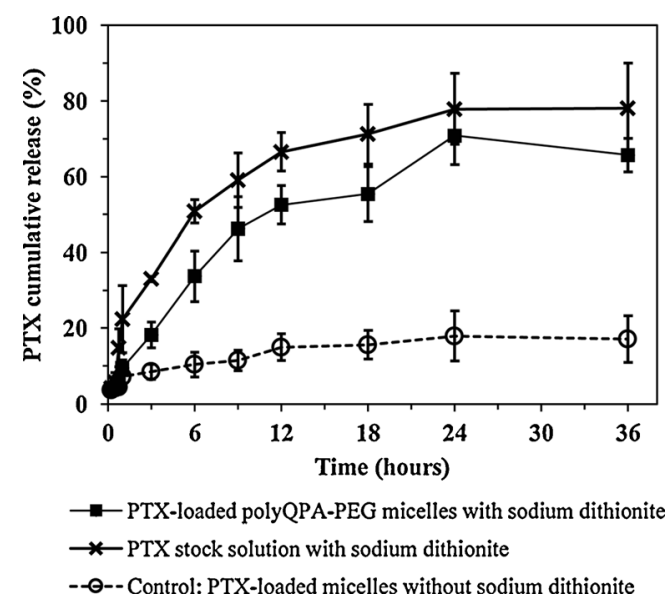

Fig. 6. Redox-triggered PTX release from polyQPA-mPEG ${ }_{750} \mathrm{mi}-$ celles in the presence (squares) and absence (circles) of sodium dithionite $(29 \mathrm{mM})$ at $37^{\circ} \mathrm{C}$. An addition of PTX solution with sodium dithionite was used as the control to compare with (crosses)
Scheme 1, hydrophobic polyQPA block was synthesized by esterification between QPA-serinol and adipoyl chloride as previously reported $(7,22)$. The esterification occurred by the reaction between two hydroxyls in QPA-serinol and reactive two acyl chloride groups in adipoyl chloride. For the following end-capping of polyQPA with $\mathrm{mPEG}$, both terminal functional groups needed to be identically reactive towards the hydroxyl group of mPEG. Since terminal functional groups of polyQPA could be either hydroxyl or acyl chloride, an additional amount of adipoyl chloride was added to secure reactive acyl chloride groups at both ends. The activated polyQPA was reacted with dried $\mathrm{mPEG}_{750}$ to obtain redox-sensitive amphiphilic polyQPA-mPEG. Based on molecular weight analysis, molecular weights of polyQPA$\mathrm{mPEG}_{750}$ and polyQPA, 3640 and 2482, respectively, may indicate that polyQPA-mPEG $\mathrm{F}_{750}$ possesses a mixture of triblock copolymer and diblock copolymer with consideration of mPEG molecular weight 750 .

Self-assembling of polyQPA-mPEG ${ }_{750}$ into micelles was supported by demonstration of CMC. The CMC of polyQPA$\mathrm{mPEG}_{750}$ was $0.039 \% \mathrm{w} / \mathrm{v}$, which is lower than commercially available amphiphilic tri-block copolymers, poly(ethylene glycol)-poly(propylene glycol)-poly(ethylene glycol) (Pluronic $\AA$ ). CMCs of Pluronic $®$ polymers range from $0.6 \%$ to $4 \%$ (35). Particularly, Pluronic ${ }^{\circledR}$ L64 (MW of 3400 and a PEG content of $40 \%$ ), which has molecular characteristics similar to polyQPA-mPEG 750 (MW of 3600 and a PEG content of $41 \%$ ), has a CMC of $4 \% w / v$. It is well established that self-assembling of amphiphilic block copolymers into micelles is primarily dependent on the nature and length of hydrophobic block $(35,36)$. The determined CMC of polyQPA-mPEG ${ }_{750}$ lower than that of Pluronic ${ }^{\circledR}$ L64 may indicate that polyQPA is more hydrophobic than poly(propylene glycol).

Particle size of polyQPA-mPEG ${ }_{750}$ measured by dynamic light scattering has shown that micellar sizes of drug-free and drug-loaded micelles were in a range between 20 and $100 \mathrm{~nm}$. It should also be noted that the size of PTX-free polyQPA$\mathrm{mPEG}_{750}$ micelles was smaller than that of drug-loaded micelles. It has been reported that loading a hydrophobic drug in the core of polymer micelle often expands micelles and increases micelle size (37). PolyQPA-mPEG 750 micelles, 

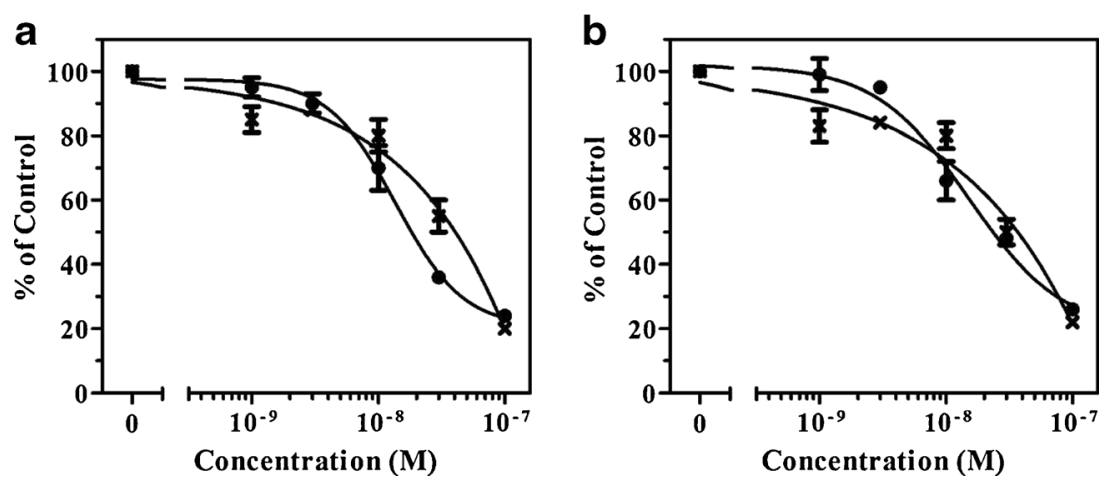

Fig. 7. Effects of paclitaxel loaded micelles on human breast tumor cell proliferation/ viability determined by SRB method: a MDA-MB-231 cells. b T47D cells. Exponentially grown T47D and MDA-MB-231 cells were exposed to the different concentration of PTXloaded micelles (circles) and PTX (crosses) for $24 \mathrm{~h}$ under normoxic condition (95\% air: $\left.5 \% \mathrm{CO}_{2}\right)$. Data shown are average standard deviation $(n=3)$

both drug-free and drug-loaded, were smaller than other nanocarriers with QPA redox switches such as liposome (21) and nanoparticles (22) of which particles sizes were $\sim 100$ and $249.8 \mathrm{~nm}$, respectively. It has been suggested that drug carriers within a size range between 10 and $200 \mathrm{~nm}$ would avoid reticuloendothelial system (RES)-mediated particle clearance, which would be beneficial for a prolonged systemic circulation (38). Considering particle size and protective PEG brushes on surface, polyQPA-mPEG ${ }_{750}$ micelles would be useful for drug delivery applications.

Generally, hydrophobic drug loading into micellar structures is affected by molecular interactions between a drug and hydrophobic micelle core and steric factors (39). In this study, paclitaxel was utilized as a model hydrophobic drug to assess the application of prepared micelles to drug delivery. Our previous publication reported that the Flory-Huggins interaction parameter $(\chi)$ between polyQPA and PTX was estimated to be 0.031 by solubility parameters calculated from the molecular dynamic simulations, suggesting a good miscibility (22). Indeed, a relatively high PTX loading efficiency of $82.5 \%$ as well as a drug loading content of $18 \%$ was achieved with polyQPA-mPEG ${ }_{750}$ micelles. Such favorable drug loading might cause more than twofold increase in micelle size from 27.50 to $79.92 \mathrm{~nm}$, which is comparable to other biodegradable polymer micelles incorporated with hydrophobic drugs (38).

For a successful application of polyQPA-mPEG ${ }_{750}$ micelles as a drug delivery system, redox-triggered dissembling of the micelles and subsequent drug release are very important. Therefore, polyQPA-mPEG ${ }_{750}$ micelles were tested for their redox-triggered dimensional changes and drug release. As illustrated in Scheme 2, drug-incorporated micelles are stable in the absence of sodium dithionite. However, in the presence of sodium dithionite, these micelles are expected to expand upon initiation of QPA reduction in the hydrophobic core thereby releasing the entrapped drug. It has been previously reported that hydrophobic polyQPA undergoes a solubility reversal by exposing free amine groups after QPA lactone release via spontaneous intra molecular cyclization in the presence of the redox trigger $(7,22)$. With protonation of exposed free amine groups in $\mathrm{pH}$ 7.4, the size of polymeric micelles should increase by swelling due to the repulsive ionic interactions introduced after the removal of
QPA lactone. As expected, polyQPA-mPEG ${ }_{750}$ micelles started to rapidly swell to reach $3338 \mathrm{~nm}$ (PI 1.0) within 30 min after the initiation of QPA reduction, indicating that micelle cores were swollen because of polymer hydration induced by the solubility reversal occurred in the polyQPA block. Swollen micelles with loosely interwoven polymer chains in the core would be able to facilitate the release of incorporated PTX. This unique property of redox-triggered dimensional changes in polyQPA-mPEG ${ }_{750}$ micelles may be useful for targeted drug delivery to the tissues with altered redox state such as tumors.

Redox-triggered structural change in polyQPA-mPEG $\mathrm{m}_{750}$ was also examined by NMR measurements to mechanistically correlate the effect of the redox trigger on the molecular property changes in the polymer which could be related to drug release. Yellow polyQPA-mPEG 750 solution became colorless implying that QPA groups were reduced to hydroquinone. The NMR spectrum recorded at $30 \mathrm{~min}$ after the addition of sodium dithionite showed characteristic proton peaks of QPA lactone, reduced polyQPA-mPEG ${ }_{750}$ backbone, and partially reduced quinone (Fig. 4B-2). In particular, the characteristic QPA lactone peaks (Fig. 4B-3) recoded in $3 \mathrm{~h}$ appeared after polymer reduction match with the peaks in the NMR spectrum measured with QPA lactone control (Fig. 4B-4), which indicates successful QPA group reduction. Combining the experimental results of redox-triggered dimensional changes in micelles and structural changes in polyQPA-mPEG 750 , the redox-responsive polyQPA$\mathrm{mPEG}_{750}$ micelles could be swollen by redox-triggered QPA lactone release within $30 \mathrm{~min}$ as presented in Scheme 2.

Quantitative analysis of lactone was assessed to get further informative insight into the underlying physical and chemical reduction processes of redox-responsive micelles, which can be eventually translated into drug release. The QPA lactone release profile in Fig. 5 has clearly demonstrated that most QPA in the core of polyQPA-mPEG ${ }_{750}$ micelles was a lactone form in the presence of sodium dithionite regardless of polymer concentration. This result is consistent with QPA reduction on polyQPA-mPEG ${ }_{750}$ characterized by NMR measurements (Fig. 4). It also worth mentioning that PEG block attachment did not affect QPA lactone release from polyQPA. QPA lactone release from polyQPA$\mathrm{mPEG}_{750}$ micelles was similar to that from polyQPA NPs 


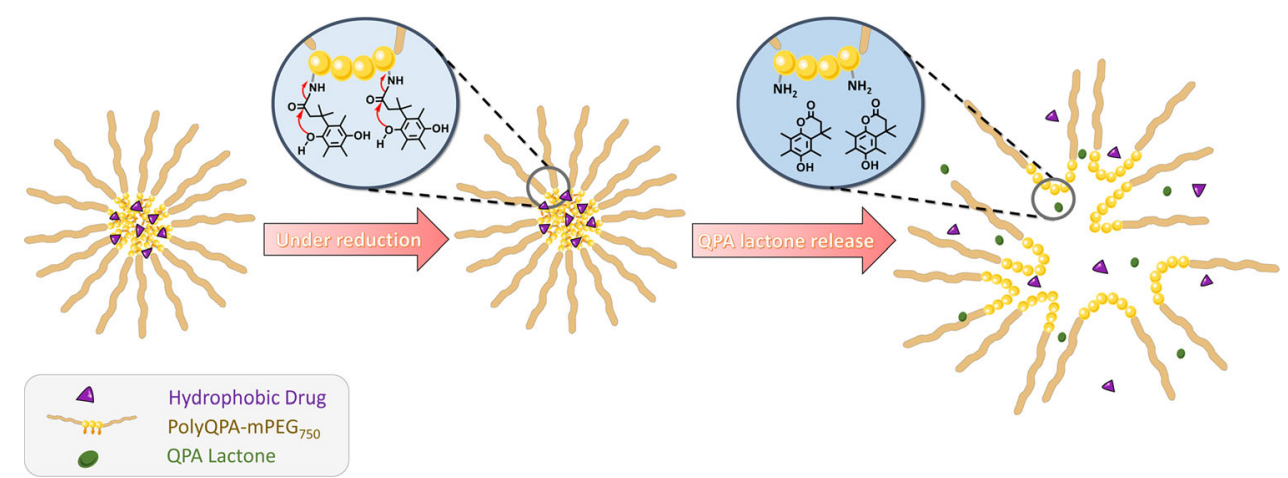

Scheme 2. Schematic illustration of drug release from redox-responsive polyQPA-mPEG ${ }_{750}$ micelles upon redox-triggered QPA reduction

$(7,22)$. Considering the degradation of polyQPA-mPEG 750 backbone chain, a change of its hydrophobicity due to carboxylic acid ends liberated by cleavage of their ester bonds will facilitate the reduction of QPA group which leads to an immediate QPA lactone release (Fig. 5). As shown in Fig. 5, enzymatic reduction of polyQPA- $\mathrm{MPEG}_{750}$ was noticeably different from that with sodium dithionite. A redox enzyme often upregulated in tumors and DTdiaphorase could release QPA lactone from polyQPA$\mathrm{mPEG}_{750}$. However, the enzymatic QPA reduction on polyQPA-mPEG 750 was clearly affected by polymer concentration, indicating that a steric factor is involved in DTdiaphorase-mediated QPA reduction from polyQPA$\mathrm{mPEG}_{750}$ as seen in Fig. 5. DT-diaphorase was able to reduce QPA on polyQPA-mPEG ${ }_{750}$ when the polymer concentration, $0.01 \%$, was below $\mathrm{CMC}, 0.039 \% w / v$. When polymer concentration, $0.5 \%$, increased to above CMC, however, DTdiaphorase was not effective in reducing QPA groups. This result indicates that the enzyme had a limited access to QPA groups on polyQPA-mPEG ${ }_{750}$ when the polymer assembled into micelles. The QPA groups in the hydrophobic block would be hidden inside the micelle core and also masked by the PEG layer on micelle surface. This explanation may be valid based on the reported work with N-(2hydroxypropyl)methacrylamide micelles containing hydrophobic oligopeptide side chains. Ulbrich et al. demonstrated that the penetration of enzyme into micelle core was impeded by structural hindrance, thereby preventing the effective enzyme binding to substrate (40). However, hydrophilic PEG blocks might contribute to increasing water solubility of polyQPA and facilitating the binding between DTdiaphorase and QPA groups on polyQPA-mPEG 750 under a polymer concentration below CMC since most polymer molecules exist as a unimer instead of being associated. The collective results also indicated the process of QPA lactonization plays an important role during the destabilization process of micelle, thereby enabling the release of loaded drug.

In vitro PTX release kinetics, indeed, was well correlated with QPA reduction and QPA lactone release previously discussed. PTX release from polyQPA-mPEG ${ }_{750}$ micelles in the presence of sodium dithionite was significantly $(p<0.01)$ greater than drug release in the absence of the redox chemical (Fig. 6). PTX release from the micelles was even very similar to that from the control, PTX solution itself (twotailed $t$ test, $p>0.2$ ) assuring that most of incorporated drug was released from the polyQPA-mPEG ${ }_{750}$ micelles over a period of experiment time in the presence of the redox chemical. Overall, a cumulative PTX release of greater than $80 \%$ was comparable to that reported from our previous work with polyQPA NPs (22). Based on the results presented in Figs. 5 and 6, PTX-loaded redox-responsive polyQPA$\mathrm{mPEG}_{750}$ micelles were stable in aqueous environments and able to release the incorporated PTX by redox-triggered QPA reduction which disrupted micelle structure.

The antitumor activity of polyQPA-mPEG ${ }_{750}$ micelles was studied in human breast tumor T47D and MDA-MB-231 cells to determine cancer cell-mediated drug release. Free PTX was used as positive controls for the study. As shown in Fig. 7, a concentration-dependent cell-killing effect was shown for PTX-loaded micelles. These PTX-loaded micelles inhibited cell proliferation and viability to the comparable extent as that observed in the presence of PTX. This indicated that all incorporated PTX has been released from polyQPA-mPEG ${ }_{750}$ micelles to limit cell growth. The antitumor activity of these polyQPA-mPEG ${ }_{750}$ micelles can be enhanced by decorating the hydroxyl end of redox-responsive micelle, polyQPA-mPEG ${ }_{750}$, with a targeting ligand such as antibody fragment and folic acid which improve its specificity for drug delivery through active pathway $(41,42)$. These polyQPA-mPEG ${ }_{750}$ micelles have integrated features including relatively high drug loading, micellar stability, redoxtriggered dimensional change, and redox-mediated drug release, which collectively provide a useful delivery platform for cytotoxic cancer drugs.

\section{CONCLUSION}

A novel redox-responsive amphiphilic polymer comprising QPA redox switches and hydrophilic mPEG, polyQPA$\mathrm{mPEG}_{750}$, was successfully synthesized and characterized. Coupling of mPEG to hydrophobic polyQPA provided polyQPA-mPEG ${ }_{750}$ with improvement of water solubility as well as self-assembling capability into micelles. Furthermore, incorporation of QPA redox switches into amphiphilic polymer led to unique micelles which enable to rapidly undergo dimensional changes upon QPA reduction and thus release incorporated drug in a redox-triggered manner. PTX- 
loaded polyQPA-mPEG 750 micelles, indeed, has demonstrated a redox-responsive drug release. Redox-responsive polyQPA-mPEG $\mathrm{F}_{750}$ micelles may be useful as a drug delivery system targeting tumor microenvironments which frequently show altered redox state and/or redox enzyme upregulation.

\section{ACKNOWLEDGMENTS}

We acknowledge that funding for this work came from Department of Defense W81XWH-10-1-0414 and National Science Foundation EPS-0903787 (S.J.). We also acknowledge the HRSA grant of which the Malvern Zetasizer was purchased.

\section{REFERENCES}

1. Allen TM, Cullis PR. Drug delivery systems: entering the mainstream. Science. 2004;303(5665):1818-22.

2. Danhier F, Feron O, Préat V. To exploit the tumor microenvironment: passive and active tumor targeting of nanocarriers for anti-cancer drug delivery. J Control Release. 2010;148(2):135-46.

3. Maeda $\mathrm{H}$. The enhanced permeability and retention (EPR) effect in tumor vasculature: the key role of tumor-selective macromolecular drug targeting. Adv Enzym Regul. 2001;41(1):189-207.

4. Garripelli VK, Kim J-K, Namgung R, Kim WJ, Repka MA, Jo S. A novel thermosensitive polymer with $\mathrm{pH}$-dependent degradation for drug delivery. Acta Biomater. 2010;6(2):477.

5. Kim J-K, Anderson J, Jun H-W, Repka MA, Jo S. Selfassembling peptide amphiphile-based nanofiber gel for bioresponsive cisplatin delivery. Mol Pharm. 2009;6(3):978-85.

6. Grüll $\mathrm{H}$, Langereis S. Hyperthermia-triggered drug delivery from temperature-sensitive liposomes using MRI-guided high intensity focused ultrasound. J Control Release. 2012;161(2):317-27.

7. Cho H, Bae J, Garripelli VK, Anderson JM, Jun H-W, Jo S. Redox-sensitive polymeric nanoparticles for drug delivery. Chem Commun. 2012;48(48):6043-5. doi:10.1039/c2cc31463k.

8. Valko M, Leibfritz D, Moncol J, Cronin MTD, Mazur M, Telser J. Free radicals and antioxidants in normal physiological functions and human disease. Int $\mathrm{J}$ Biochem Cell Biol. 2007;39(1):44-84.

9. Phillips DJ, Gibson MI. Redox-sensitive materials for drug delivery: targeting the correct intracellular environment, tuning release rates, and appropriate predictive systems. Antioxid Redox Signal. 2014;21(5):786-803. doi:10.1089/ars.2013.5728.

10. Saito G, Swanson JA, Lee K-D. Drug delivery strategy utilizing conjugation via reversible disulfide linkages: role and site of cellular reducing activities. Adv Drug Deliv Rev. 2003;55(2):199_ 215.

11. Huo M, Yuan J, Tao L, Wei Y. Redox-responsive polymers for drug delivery: from molecular design to applications. Polym Chem. 2014;5(5):1519-28. doi:10.1039/c3py01192e.

12. Cho YW, Lee J, Lee SC, Huh KM, Park K. Hydrotropic agents for study of in vitro paclitaxel release from polymeric micelles. J Control Release. 2004;97(2):249-57. doi:10.1016/ j.jconrel.2004.03.013.

13. Volpato M, Abou-Zeid N, Tanner RW, Glassbrook LT, Taylor J, Stratford I, et al. Chemical synthesis and biological evaluation of a $\mathrm{NAD}(\mathrm{P}) \mathrm{H}$ :quinone oxidoreductase-1-targeted tripartite quinone drug delivery system. Mol Cancer Ther. 2007;6(12):312230. doi:10.1158/1535-7163.mct-07-0519.

14. Fuhrhop JH, Hungerbuehler H, Siggel U. Quinone-containing amphiphiles and bolaform amphiphiles that form redox-active lipid membranes. Langmuir. 1990;6(7):1295-300.

15. Levine MN, Raines RT. Trimethyl lock: a trigger for molecular release in chemistry, biology, and pharmacology. Chem Sci. 2012;3(8):2412-20. doi:10.1039/c2sc20536j.
16. Schlager JJ, Powis G. Cytosolic NAD(P)H:(quinoneacceptor)oxidoreductase in human normal and tumor tissue: effects of cigarette smoking and alcohol. Int $\mathrm{J}$ Cancer. 1990;45(3):403-9. doi:10.1002/ijc.2910450304.

17. Bey EA, Bentle MS, Reinicke KE, Dong Y, Yang C-R, Girard L, et al. An NQO1- and PARP-1-mediated cell death pathway induced in non-small-cell lung cancer cells by $\beta$-lapachone. Proc Natl Acad Sci U S A. 2007;104(28):11832-7. doi:10.1073/ pnas.0702176104.

18. Danson S, Ward TH, Butler J, Ranson M. DT-diaphorase: a target for new anticancer drugs. Cancer Treat Rev. 2004;30(5):437-49. doi:10.1016/j.ctrv.2004.01.002.

19. Mendoza MF, Hollabaugh NM, Hettiarachchi SU, McCarley RL. Human NAD(P)H:quinone oxidoreductase type I (hNQO1) activation of quinone propionic acid trigger groups. Biochemistry. 2012;51(40):8014-26. doi:10.1021/bi300760u.

20. Pitchuanchom S, Songsiang U, Weerapreeyakul N, Yenjai C. Anticancer activity of the bioreductive and non-bioreductive zerumbone derivatives. Lett Drug Des Discovery. 2011;8(6):53643.

21. Ong W, Yang Y, Cruciano AC, McCarley RL. Redox-triggered contents release from liposomes. J Am Chem Soc. 2008;130(44):14739-44.

22. Bae J, Nael MA, Jiang L, Hwang PT, Mahdi F, Jun H-W, et al. Quinone propionic acid-based redox-triggered polymer nanoparticles for drug delivery: Computational analysis and in vitro evaluation. J Appl Polym Sci. 2014;131(13):40461. doi:10.1002/ app.40461.

23. Yoo J-W, Chambers E, Mitragotri S. Factors that control the circulation time of nanoparticles in blood: challenges, solutions and future prospects. Curr Pharm Des. 2010;16(21):2298-307.

24. Brigger I, Dubernet C, Couvreur P. Nanoparticles in cancer therapy and diagnosis. Adv Drug Deliv Rev. 2002;54(5):631-51.

25. Moghimi SM, Hunter AC, Murray JC. Long-circulating and target-specific nanoparticles: theory to practice. Pharmacol Rev. 2001;53(2):283-318.

26. Davis S. Biomedical applications of nanotechnology-implications for drug targeting and gene therapy. Trends Biotechnol. 1997;15(6):217-24.

27. Kim SC, Kim DW, Shim YH, Bang JS, Oh HS, Kim SW, et al. In vivo evaluation of polymeric micellar paclitaxel formulation: toxicity and efficacy. J Control Release. 2001;72(1-3):191-202. doi:10.1016/S0168-3659(01)00275-9.

28. Kim JK, Garripelli VK, Jeong UH, Park JS, Repka MA, Jo S. Novel $\mathrm{pH}$-sensitive polyacetal-based block copolymers for controlled drug delivery. Int J Pharm. 2010;401(1-2):79-86. doi:10.1016/j.ijpharm.2010.08.029.

29. Ahn JS, Suh JM, Lee M, Jeong B. Slow eroding biodegradable multiblock poloxamer copolymers. Polym Int. 2005;54(5):842-7.

30. Wang Y, Yu L, Han L, Sha X, Fang X. Difunctional pluronic copolymer micelles for paclitaxel delivery: synergistic effect of folate-mediated targeting and pluronic-mediated overcoming multidrug resistance in tumor cell lines. Int $\mathrm{J}$ Pharm. 2007;337(1-2):63-73.

31. Li J, Mahdi F, Du L, Datta S, Nagle DG, Zhou Y-D. mitochondrial respiration inhibitors suppress protein translation and hypoxic signaling via the hyperphosphorylation and inactivation of translation initiation factor eIF $2 \alpha$ and elongation factor eEF2. J J Nat Prod. 2011;74(9):1894-901. doi:10.1021/np200370z.

32. Rubinstein LV, Shoemaker RH, Paull KD, Simon RM, Tosini S, Skehan P, et al. Comparison of In vitro anticancer-drug-screening data generated with a tetrazolium assay versus a protein assay against a diverse panel of human tumor cell lines. J Natl Cancer Inst. 1990;82(13):1113-7. doi:10.1093/jnci/82.13.1113.

33. Carpino LA, Triolo SA, Berglund RA. Reductive lactonization of strategically methylated quinone propionic acid esters and amides. J Org Chem. 1989;54(14):3303-10. doi:10.1021/ jo00275a012.

34. Ong W, McCarley RL. Redox-driven shaving of dendrimers. Chem Commun. 2005;37:4699-701.

35. Alexandridis P, Holzwarth JF, Hatton TA. Micellization of poly (ethylene oxide)-poly (propylene oxide)-poly (ethylene oxide) triblock copolymers in aqueous solutions: thermodynamics of copolymer association. Macromolecules. 1994;27(9):2414-25. 
36. Croy SR, Kwon GS. The effects of pluronic block copolymers on the aggregation state of nystatin. J Control Release. 2004;95(2):161-71.

37. Huh KM, Min HS, Lee SC, Lee HJ, Kim S, Park K. A new hydrotropic block copolymer micelle system for aqueous solubilization of paclitaxel. J Control Release. 2008;126(2):122-9.

38. Kim SY, Shin ILG, Lee YM, Cho CS, Sung YK. Methoxy poly(ethylene glycol) and $\epsilon$-caprolactone amphiphilic block copolymeric micelle containing indomethacin.: II. Micelle formation and drug release behaviours. J Control Release. 1998;51(1):13-22. doi:10.1016/S0168-3659(97)00124-7.
39. Sezgin Z, Yüksel N, Baykara T. Preparation and characterization of polymeric micelles for solubilization of poorly soluble anticancer drugs. Eur J Pharm Biopharm. 2006;64(3):261-8.

40. Ulbrich K, Koňák Č, Tuzar Z, Kopeček J. Solution properties of drug carriers based on poly [N-(2-hydroxypropyl) methacrylamide] containing biodegradable bonds. Die Makromol Chem. 1987;188(6):1261-72.

41. Xiong J, Meng F, Wang C, Cheng R, Liu Z, Zhong Z. Folateconjugated crosslinked biodegradable micelles for receptormediated delivery of paclitaxel. J Mater Chem. 2011;21(15):5786-94. doi:10.1039/c0jm04410e.

42. Ruoslahti E, Bhatia SN, Sailor MJ. Targeting of drugs and nanoparticles to tumors. J Cell Biol. 2010;188(6):759-68. 